
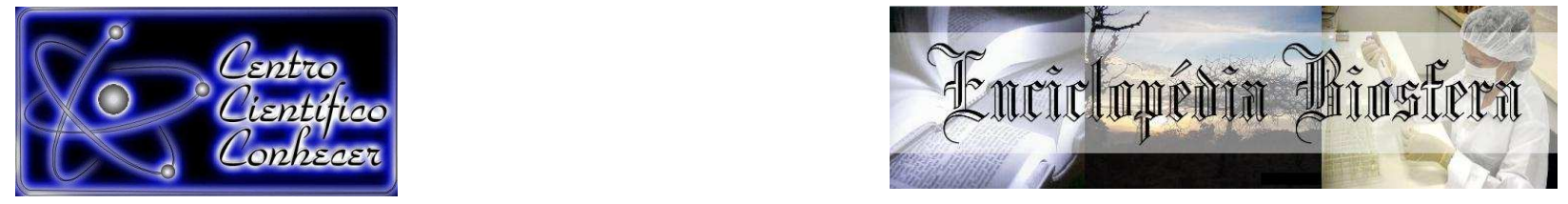

\title{
ATRIBUTOS QUÍMICOS DE UM ESPODOSSOLO FERROCÁRBICO NO SISTEMA INDÍGENA DE PRODUÇÃO DE MANDIOCA
}

Bruno Vinícius Castro Guimarães ${ }^{1}$, Jairo Costa Fernandes ${ }^{2}$, Sérgio Luiz Rodrigues Donato $^{3}$, Elias Brasilino de Souza ${ }^{4}$, Maycon Murilo Castro Guimarães ${ }^{5}$

1 Professor Mestre do Instituto Federal do Amazonas (bvinicius20@yahoo.com.br) Campus São Gabriel da Cachoeira, Amazonas-Brasil

2,3 Professor Doutor do Instituto Federal Baiano

4 Professor Mestre do Instituto Federal do Amazonas

5 Engenheiro Agrônomo Mestre da Universidade Estadual do Sudoeste da Bahia

Recebido em: 08/09/2015 - Aprovado em: 14/11/2015 - Publicado em: 01/12/2015

DOI: http://dx.doi.org/10.18677/Enciclopedia_Biosfera_2015_091

\begin{abstract}
O diagnóstico da fertilidade do solo, em diferentes tempos de pousio, pode subsidiar as recomendações de uso dos recursos internos à comunidade em detrimento de insumos externos para aumentar a sustentabilidade do sistema de cultivo. Objetivouse com o presente estudo avaliar os atributos químicos de um Espodossolo Ferrocárbico, em função do tempo de pousio em áreas cultivadas com mandioca. $A$ pesquisa foi desenvolvida ano agrícola 2012, na comunidade indígena Tukano de Tapira Ponta, na margem do Rio Waupés, região do Alto Rio Negro, São Gabriel da Cachoeira, Amazonas. Os cinco tratamentos, área de floresta natural, roça de mandioca recém-colhida, área com um ano de pousio, área com dois anos de pousio e área com três anos de pousio foram dispostos num delineamento inteiramente casualizado, com três repetições. Os teores de cálcio $(\mathrm{Ca})$ e magnésio $(\mathrm{Mg})$ foram similares entre as áreas estudadas. O tempo de pousio de um, dois ou três anos utilizado na agricultura indígena, em áreas cultivadas com mandioca é insuficiente para recomposição dos atributos químicos de um Espodossolo Ferrocárbico. Áreas com floresta natural ou que passaram pelo pousio de um, dois ou três anos apresentam $\mathrm{pH}$ menos ácido que as áreas de mandioca recém-colhida. Os manejos de pousio adotados não diminuem a saturação por alumínio dos solos.
\end{abstract}

RESUMO

PALAVRAS-CHAVE: conservação, fertilidade, manejo.

\section{CHEMICAL PROPERTIES OF A FERROCARBIC SPODOSOL IN INDIGENOUS CASSAVA PRODUCTION SYSTEM}

\begin{abstract}
Diagnosis of soil fertility, at different times of fallow, can support the recommended use of internal resources to the community at the expense of external inputs to increase the sustainability of the farming system. The present study aimed to evaluate the chemical attributes of a Spodosol Ferrocarbic, depending on the fallow time in areas planted with cassava. The research was developed agricultural year 2012, the Tukano indigenous community Tapira Ponta, on the shore of Waupés River, the Alto Rio Negro region, São Gabriel da Cachoeira, Amazonas. The five treatments
\end{abstract}


- area of natural forest, recently harvested cassava fields, an area with one year of fallow, an area with two years of fallow and an area with three years of fallow - were arranged in a completely randomized design with three replications. The contents of calcium $(\mathrm{Ca})$ and magnesium $(\mathrm{Mg})$ were similar between the studied areas. The fallow period of one, two or three years used in indigenous agriculture in areas planted with cassava is insufficient for recovery of chemical attributes of a Spodosol Ferrocarbic. Areas with natural forest or areas that have gone through the fallow of one, two or three years have $\mathrm{pH}$ less acidic than the areas of newly harvested cassava. The managements adopted fallow do not diminish the aluminum saturation of the soil.

KEYWORDS: conservation, fertility, management.

\section{INTRODUÇ̃̃O}

A cultura da mandioca (Manihot esculenta Crantz) foi largamente cultivada pelas populações indígenas que habitavam a divisa entre a Amazônia e o Cerrado antes do descobrimento (PIPERNO, 2011), sendo os responsáveis por disseminá-la na América. Os indígenas amazônidas utilizam a mandioca como a principal fonte de alimentação na fabricação de farinha, na obtenção da massa de carimã (utilizada em bolo), no beiju (variação da tapioca) ou ainda, na produção de uma farinha que se chama uitan (EMPERAIRE et al., 2010; EMPERAIRE, 2013; EMPERAIRE \& ELOY, 2015).

A cultura é originária do Brasil e, por isso está presente em todo o território nacional. A região Norte sobressai-se com uma participação de $34,3 \%$, e as demais regiões, contribuem na produção nacional percentualmente com: Nordeste $(24,9 \%)$, Sul (24,0\%), Sudeste (10,2\%) e Centro-Oeste (6,0\%) (IBGE, 2015).

Na Amazônia, o sistema de manejo do solo ainda utilizado é o da agricultura de corte e queima, também chamado de itinerante. É a agricultura tradicional na região, desenvolvida em áreas pequenas (máximo de 1 ha), pelos pequenos agricultores, que trabalham exclusivamente com mão de obra familiar e que são responsáveis pela maior parte da produção agrícola regional (FREITAS et al., 2011; GROXKO, 2011).

A região caracteriza-se por uma enorme variedade de microecossistemas, bem como por uma restrição generalizada de nutrientes (Oligotrofia). Possui formações florestais de terra firme, igapós (florestas inundadas) e campinarana, esta última também conhecida como caatinga do rio Negro, um tipo de vegetação peculiar à região. A caatinga do rio Negro é predominante na região e seus solos são extremamente ácidos, arenosos e lixiviados, características de um Espodossolo. As comunidades indígenas estão geralmente localizadas nas regiões de ocorrências de matas de terra firme, cujos solos permitem o aproveitamento agrícola. Por este motivo, há grandes extensões de terras no interior das áreas indígenas que são pouco habitadas (FOIRN, 2010).

O sistema de cultivo indígena, construído ao longo de milhares de anos, não pode ser ignorado quando se fala em conservar, melhorar e produzir mandioca, uma das mais importantes alternativas para o combate à fome no mundo (SILVA \& MURRIETA, 2014).

Segundo os estudos desenvolvidos por FRASER (2010) e FRASER et al., (2012), no processo de corte e queima, a vegetação remanescente no período de pousio é queimada, e em seguida, as culturas semeadas utilizam os nutrientes liberados através da biomassa mineralizada. No entanto, apesar desta primeira fertilização através das cinzas ricas em cátions úteis para as plantas, com o passar 
dos anos, ocorre redução da fertilidade do solo e diminuição da produtividade das culturas.

A mandioca absorve grandes quantidades de nutrientes e praticamente exporta tudo o que foi absorvido, quase nada é retornado ao solo sob a forma de resíduos culturais. MATTOS \& BEZERRA (2003), determinaram que, para uma produção de 25 toneladas de raízes + parte aérea de mandioca, por hectare são extraídos $123 \mathrm{~kg}$ de nitrogênio $(\mathrm{N}), 27 \mathrm{~kg}$ de fósforo $(\mathrm{P}), 146 \mathrm{~kg}$ de potássio $(\mathrm{K}), 46 \mathrm{~kg}$ de cálcio $(\mathrm{Ca})$, $20 \mathrm{~kg}$ de magnésio (Mg) e $18 \mathrm{~kg}$ de enxofre (S); assim, a ordem decrescente de absorção de nutrientes é a seguinte: $\mathrm{K}>\mathrm{N}>\mathrm{Ca}>\mathrm{P}>\mathrm{Mg}>\mathrm{S}$. Considerando a alta pluviosidade na região amazônica, e sob a ação de corte e queima, o solo desprotegido vem perdendo, por processos de lixiviação e erosão, os nutrientes contidos nas cinzas (SAMPAIO et al., 2003).

A vegetação possui grande capacidade de reconstituição, repondo a biomassa anterior, porém, com o tempo de pousio reduzido, a reposição dos nutrientes se faz de maneira lenta e incompleta, por haver a quebra do sistema planta-solo-planta provocando o decréscimo das produções (PARRY et al., 2005).

O diagnóstico da fertilidade do solo, em diferentes tempos de pousio, pode constituir a base para recomendações de recursos internos à comunidade. Diante do exposto, objetivou-se com o presente estudo avaliar os atributos químicos de um Espodossolo Ferrocárbico, em função do tempo de pousio em áreas cultivadas com mandioca.

\section{MATERIAL E MÉTODOS}

A pesquisa foi desenvolvida no ano agrícola 2012, na comunidade indígena Tukano de Tapira Ponta, situada na margem do Rio Waupés, região do Alto Rio Negro, município de São Gabriel da Cachoeira, Amazonas. A área de estudo está localizada geograficamente nas coordenadas $00^{\circ} 14^{\prime} 45^{\prime \prime}$ de latitude Norte e 69²4'13" de longitude Oeste, com altitude média de $118 \mathrm{~m}$.

De acordo com a classificação de Köppen, o clima da região é do tipo Af, quente e úmido. A precipitação e a temperatura média anual, no período de 2010 a 2014, foi de $3.191 \mathrm{~mm}$ (GUIMARÃES et al., 2015) e $25^{\circ} \mathrm{C}$, respectivamente. O solo da área experimental foi classificado como Espodossolo Ferrocárbico (EMBRAPA, 2013).

O sistema de cultivo adotado no presente estudo, derruba e queima da vegetação remanescente no período de pousio, é praticado a décadas pelas tribos indígenas, para utilização dos nutrientes liberados através da biomassa que foi queimada. $\mathrm{O}$ experimento foi constituído por cinco tratamentos, com três repetições, dispostos em um delineamento inteiramente casualizado.

O estudo foi realizado em três ambientes: áreas com diferentes tempos de pousio e cultivadas anteriormente com mandioca de mesa; área recém-cultivada com mandioca e uma área de floresta natural (Quadro 1). O tamanho de cada área experimental correspondia à $10.000 \mathrm{~m}^{2}$, onde foram coletadas 10 amostras simples, perfazendo, a posteriori três amostras compostas de solo, na camada arável, ou seja, nos primeiros $20 \mathrm{~cm}$ de profundidade. As amostras de solo foram coletadas em zigue-zague, utilizando-se de um cavador, distanciadas a cada $15 \mathrm{~m}$. 
QUADR01 Descrição das áreas amostradas para determinação dos atributos químicos do solo.

\begin{tabular}{cc}
\hline Áreas (A) & Descrição das áreas agrícolas amostradas \\
\hline A1 & Área de floresta natural \\
A2 & $\begin{array}{c}\text { Área com roça de mandioca } \\
\text { recém-colhida }\end{array}$ \\
A3 & Área com um 1 ano de pousio \\
& Área com 2 anos de pousio \\
& Área com 3 anos de pousio
\end{tabular}

Comunidade indígena: Tapira Ponta, São Gabriel da Cachoeira, AM, 2012.

Fotos: Bruno Guimarães, (2012)

As amostras de solo foram acondicionadas em sacos plásticos e encaminhadas ao laboratório para a determinação dos atributos químicos do solo, conforme metodologias adotadas no Laboratório de Solos e Plantas da EMBRAPA Amazônia Ocidental, em Manaus. Os atributos químicos determinados foram: $\mathrm{pH}$ (água 1:2,5); carbono orgânico (C); teores disponíveis dos macronutrientes $\mathrm{P} ; \mathrm{K} ; \mathrm{Ca}$ e Mg (EMBRAPA, 1997). Os resultados das análises químicas foram submetidos ao teste de Tukey a $5 \%$ de probabilidade, utilizando-se do programa SISVAR $\AA_{-}$ Sistema de Análise de Variância - da Universidade Federal de Lavras-UFLA (FERREIRA, 2011). 


\section{RESULTADOS E DISCUSSÃO}

Comparando os valores de $\mathrm{pH}$, nos ambientes estudados, verifica-se na Tabela 1, que o menor valor de $\mathrm{pH}$ ocorreu no tratamento A2 (área recém-colhida), enquanto os tratamentos A3 ( 1 ano de pousio) e A4 (2 anos de pousio) apresentaram os maiores valores, respectivamente.

TABELA 1 Médias e desvio padrão dos atributos químicos do Espodossolo Ferrocárbico, em diferentes áreas de cultivo da mandioca na comunidade indígena Tapira Ponta, São Gabriel da Cachoeira-AM.

\begin{tabular}{cccc}
\hline & \multicolumn{3}{c}{ Atributos químicos do solo } \\
\cline { 2 - 4 } Áreas & $\mathrm{pH} \mathrm{em} \mathrm{água}$ & Matéria orgânica $\left(\mathrm{g} \mathrm{kg}^{-1}\right)$ & $\mathrm{K}\left(\mathrm{mg} \mathrm{dm}^{-3}\right)$ \\
\hline A1 & $4,30 \pm 0,04 \mathrm{ab}$ & $46,62 \pm 3,88 \mathrm{a}$ & $20,67 \pm 0,51 \mathrm{a}$ \\
A2 & $4,01 \pm 0,23 \mathrm{~b}$ & $22,65 \pm 8,24 \mathrm{~b}$ & $17,33 \pm 0,58 \mathrm{a}$ \\
$\mathrm{A} 3$ & $4,63 \pm 0,13 \mathrm{a}$ & $33,16 \pm 14,99 \mathrm{ab}$ & $18,00 \pm 7,00 \mathrm{a}$ \\
$\mathrm{A} 4$ & $4,58 \pm 0,27 \mathrm{a}$ & $35,85 \pm 7,98 \mathrm{ab}$ & $10,00 \pm 0,00 \mathrm{~b}$ \\
$\mathrm{~A} 5$ & $4,46 \pm 015 \mathrm{ab}$ & $18,96 \pm 5,30 \mathrm{~b}$ & $21,00 \pm 8,89 \mathrm{a}$ \\
\hline CV & $4,32 \%$ & $27,93 \%$ & $29,50 \%$
\end{tabular}

Médias seguidas por letras iguais na coluna não diferem entre si, pelo teste Tukey, a $5 \%$ de probabilidade. $A 1$ = Área de floresta natural; $\mathrm{A} 2$ = Área com roça de mandioca recém-colhida; $\mathrm{A} 3$ = Área com um 1 ano de pousio; $\mathrm{A} 4$ = Área com 2 anos de pousio e A5 = Área com 3 anos de pousio. CV = Coeficiente de Variação.

Segundo LORENZI et al. (2002) para a cultura da mandioca, a faixa de $\mathrm{pH}$ ideal situa-se entre 5 e 6 . Provavelmente por isso, a correção da acidez do solo no Brasil com aplicação de calcário, de modo geral, não tem possibilitado aumentos acentuados na produção da mandioca, mesmo em solos ácidos da região dos cerrados, confirmando a tolerância da mandioca a condições de acidez.

De acordo com os valores de $\mathrm{pH}$ apresentados na Tabela 2, mesmo apresentado um menor valor de $\mathrm{pH}$ logo após a colheita - A2, provavelmente decorrente da própria extração de nutrientes com acidificação da rizosfera (BETENCOURT et al., 2012), observa-se que o solo estudado é de natureza ácida, independente do tratamento.

Independente da análise estatística, observa-se que apenas a área de floresta natural, o teor de matéria orgânica de $46,62 \mathrm{~g} \mathrm{~kg}^{-1}$ encontra-se na faixa adequada, os tratamentos A3 e A4 caracterizam como médio e os tratamentos A2 e A5 caracterizam como baixo, de acordo a recomendação de adubação e calagem para os solos tropicais e subtropicais (EMBRAPA, 2013).

Nos solos tropicais úmidos, a matéria orgânica apresenta uma estreita relação com as demais propriedades físicas, químicas e biológicas do solo. Portanto, o manejo sustentável da matéria orgânica do solo é fundamental à manutenção da capacidade produtiva do solo em longo prazo, como argumentam CIOTTA et al., (2003).

Com relação aos valores da matéria orgânica no solo, associado ao manejo tradicional indígena, verifica-se na Tabela 02 , que houve diferença estatística entre os tratamentos estudados. O tratamento $A 1$ foi o que apresentou maior teor de matéria orgânica e diferiu estatisticamente apenas dos tratamentos $A 2$ e A5, que apresentaram menores valores, mas não diferiram dos tratamentos A3 e A4. Na área sob floresta natural - A1, observa-se que os teores estão próximos ao solo ideal, que é de $50 \mathrm{~g} \mathrm{~kg}^{-1}$ (Tabela 1). 
Embora os teores de matéria orgânica entre os tratamentos, A2, A3, A4 e A5 sejam similares, observa-se que percentualmente, o nível de matéria orgânica no solo, em função dos tempos de pousio, A3 e A4, foi $46 \%$ e 58\%, respectivamente, maior que a área recém-colhida - A2. No entanto, a área A5 apresentou o menor percentual orgânico no solo.

Da análise da Tabela 1 observa-se, que os valores médios de $\mathrm{K}$ foram similares estatisticamente entre a maioria dos ambientes estudados, com exceção da área A4. Contudo, todos os tratamentos estão abaixo da faixa recomendada para a cultura da mandioca ( $<22 \mathrm{mg} \mathrm{dm}^{-3}$ de $\mathrm{K}$ ) de acordo com ZATARIM et al. (2005). Estes autores determinaram as curvas de resposta das doses de $\mathrm{K}$ para a cultura da mandioca, para elaboração de tabelas de recomendação de adubação no Mato Grosso do Sul, onde constam que os teores de $\mathrm{K}$ são considerados baixos, quando os valores estiverem abaixo de $22 \mathrm{mg} \mathrm{dm}^{-3}$, médio, quando os teores estiverem entre 23 e 33 e alto nos teores acima de $34 \mathrm{mg} \mathrm{dm}^{-3}$.

Segundo DAROLT \& OSAKI (1991) o equilíbrio deste nutriente no solo pode ser explicado pela utilização do fogo na limpeza da área, prática que disponibiliza o nutriente da biomassa para a solução do solo. Mesmo realizando a prática do fogo para a limpeza da área, verifica-se que todos os tratamentos apresentaram baixos teores de K (ZATARIM et al., 2005).

RÓS (2012) estudou a produtividade de raízes de mandioca em função de doses de $\mathrm{K}$ e verificou que a aplicação de $\mathrm{K}$ não promove incremento na produtividade de raízes de mandioca quando o solo contém elevado teor do nutriente apesar do $\mathrm{K}$ ser o nutriente exportado em maior proporção pela cultura da mandioca (MAGALHÃES et at., 2013).

Os critérios de interpretação das análises químicas de solos, atualmente, utilizados no Estado do Amazonas têm sido baseados nas recomendações do Laboratório de Solos da Embrapa Amazônia Ocidental e de modo geral os teores de $\mathrm{P}, \mathrm{Ca}, \mathrm{Mg}$ dos solos das comunidades indígenas se enquadram na classe de baixa fertilidade. Para os teores de P observa-se que não houve diferença entre as áreas estudadas e verifica-se que os teores estão abaixo do recomendado para a cultura da mandioca (Tabela 3). Os valores atestam a baixa fertilidade dos solos para $P$, sendo considerado como teor muito baixo $\left(P<20 \mathrm{mg} \mathrm{dm}^{-3}\right.$ ) (ALVES et al., 2009).

TABELA 2 Médias e desvio padrão dos atributos químicos do Espodossolo Ferrocárbico, em diferentes áreas de cultivo da mandioca na comunidade indígena Tapira Ponta, São Gabriel da Cachoeira-AM.

\begin{tabular}{cccc}
\hline & \multicolumn{3}{c}{ Atributos químicos do solo } \\
\cline { 2 - 4 } Áreas & $\mathrm{P}\left(\mathrm{mg} \mathrm{dm}^{-3}\right)$ & $\mathrm{Ca}\left(\mathrm{cmol}_{\mathrm{c}} \mathrm{dm}^{-3}\right)$ & $\mathrm{Mg}\left(\mathrm{cmol}_{\mathrm{c}} \mathrm{dm}^{-3}\right)$ \\
\hline A1 & $2,33 \pm 0,58 \mathrm{a}$ & $0,07 \pm 0,07 \mathrm{a}$ & $0,10 \pm 0,05 \mathrm{a}$ \\
A2 & $2,00 \pm 1,00 \mathrm{a}$ & $0,04 \pm 0,01 \mathrm{a}$ & $0,05 \pm 0,01 \mathrm{ab}$ \\
A3 & $5,00 \pm 4,58 \mathrm{a}$ & $0,03 \pm 0,01 \mathrm{a}$ & $0,05 \pm 0,01 \mathrm{ab}$ \\
A4 & $4,00 \pm 2,65 \mathrm{a}$ & $0,03 \pm 0,01 \mathrm{a}$ & $0,04 \pm 0,01 \mathrm{~b}$ \\
A5 & $1,00 \pm 0,00 \mathrm{a}$ & $0,03 \pm 0,02 \mathrm{a}$ & $0,05 \pm 0,03 \mathrm{a}$ \\
\hline CV & $85,10 \%$ & $83,69 \%$ & $46,31 \%$ \\
\hline
\end{tabular}

Médias seguidas por letras iguais na coluna não diferem entre si, pelo teste Tukey, a $5 \%$ de probabilidade. A1 = Área de floresta natural; $A 2$ = Área com roça de mandioca recém-colhida; $\mathrm{A} 3$ = Área com um 1 ano de pousio; $A 4$ = Área com 2 anos de pousio e A5 = Área com 3 anos de pousio. CV = Coeficiente de Variação. 
Por outro lado, segundo MAZOYER \& ROUDART (2010) a mandioca é cultivada nos mais variados tipos de solo com alta capacidade de se desenvolver e produzir relativamente bem em solos de baixa fertilidade, talvez seja a principal característica dessa planta. Supera os problemas de baixos teores de $\mathrm{P}$ no solo, através de uma eficiente associação com micorrizas. Em solos pobres de nutrientes, a planta reduz seu tamanho, mantendo, todavia, a concentração desses nutrientes em nível ótimo. Essa característica permite maior eficiência na utilização dos elementos nutritivos (TRINDADE et al., 2010).

Pela Tabela 2 verifica-se que os teores de $\mathrm{Ca}$ e $\mathrm{Mg}$ foram similares entre as áreas estudadas, com exceção para esse último elemento na área A4. Os valores estão extremamente baixos e comprometedores à nutrição mineral de plantas nos diferentes ambientes estudados. Esta situação é bastante preocupante, pois de acordo com SALLA \& CABELLO (2007) o Mg é o segundo elemento mais exportado pelas raízes da mandioca.

Adicionalmente, OTSUBO et al. (2002) afirmam que a mandioca é uma cultura com alta tolerância a acidez do solo. Além de possuir uma importante característica de se adaptar a diferentes tipos de solo, mesmo aqueles considerados relativamente pobres, como os Espodossolos localizados na floresta tropical amazônica, conforme acrescentam SILVA \& MURRIETA (2014). Todavia, a correção da acidez permite aumentar a disponibilidade de nutrientes considerados essenciais às plantas, além de fornecer algum deles, como o $\mathrm{Ca}$ e o $\mathrm{Mg}$, principalmente.

$\mathrm{Da}$ análise da Tabela 4, depreende-se que os valores da capacidade de troca de cátions do solo $(\mathrm{T})$ diferiram entre os tratamentos, sendo que a área de floresta natural apresentou resultado semelhante aos tempos de um e dois anos de pousio, o que sugere correlação positiva entre a adição da matéria orgânica no solo (Tabela 1) e os valores de T. A área de mandioca recém-colhida, juntamente com a área de três anos de pousio vegetativo, expressou a menor capacidade de troca catiônica. Os valores médios de T se deve aos teores elevados de hidrogênio e alumínio $(\mathrm{m})$, acidez potencial, pois o solo é paupérrimo em bases. Os tratamentos estudados apresentaram valores de saturação por base muito baixos, o que evidencia a necessidade de calagem para o cultivo racional da mandioca.

TABELA 3 Médias e desvio padrão dos atributos químicos do Espodossolo Ferrocárbico, em diferentes áreas de cultivo da mandioca na comunidade indígena Tapira Ponta, São Gabriel da Cachoeira-AM.

\begin{tabular}{cccc}
\hline & \multicolumn{3}{c}{ Atributos químicos do solo } \\
\cline { 2 - 4 } Áreas & $\mathrm{T}\left(\mathrm{cmol}_{\mathrm{c}} \mathrm{dm}^{-3}\right)$ & $\mathrm{V}(\%)$ & $\mathrm{m}(\%)$ \\
\hline A1 & $10,09 \pm 1,23 \mathrm{a}$ & $2,25 \pm 1,87 \mathrm{a}$ & $90,57 \pm 7,73 \mathrm{a}$ \\
A2 & $6,79 \pm 1,32 \mathrm{~b}$ & $1,94 \pm 0,16 \mathrm{a}$ & $93,90 \pm 0,20 \mathrm{a}$ \\
A3 & $8,89 \pm 3,34 \mathrm{ab}$ & $1,25 \pm 0,15 \mathrm{a}$ & $95,54 \pm 0,92 \mathrm{a}$ \\
A4 & $8,04 \pm 2,87 \mathrm{ab}$ & $1,41 \pm 0,53 \mathrm{a}$ & $94,63 \pm 1,84 \mathrm{a}$ \\
A5 & $4,43 \pm 1,36 \mathrm{~b}$ & $2,77 \pm 046 \mathrm{a}$ & $93,34 \pm 3,03 \mathrm{a}$ \\
\hline CV & $29,00 \%$ & $49,43 \%$ & $4,04 \%$ \\
\hline
\end{tabular}

Médias seguidas por letras iguais na coluna não diferem entre si, pelo teste Tukey, a $5 \%$ de probabilidade. $A 1$ = Área de floresta natural; $A 2$ = Área com roça de mandioca recém-colhida; $\mathrm{A} 3$ = Área com um 1 ano de pousio; $\mathrm{A} 4$ = Área com 2 anos de pousio e A5 = Área com 3 anos de pousio. CV = Coeficiente de Variação.

Com relação à saturação por $m$ (Tabela 3 ), verifica-se que em todos os ambientes, encontra-se acima de $50 \%$, o que caracteriza solos muito ácidos (álicos, ENCICLOPÉDIA BIOSFERA, Centro Científico Conhecer - Goiânia, v.11 n.22; p.382 2015 
$m>50 \%$ ). O tempo de pousio não foi suficiente para que saturação por $m$ trocável diminuísse. Assim, é necessário realizar calagem em todas as áreas amostradas, no intuito de adicionar óxidos de $\mathrm{Ca}$ e $\mathrm{Mg}$ para gerar hidroxila e precipitar o $\mathrm{m}$ trocável que se encontra muito elevado e suprir $\mathrm{Ca}$ e $\mathrm{Mg}$, cujos teores estão extremamente baixos.

\section{CONCLUSÕES}

O tempo de pousio de um, dois ou três anos utilizado na agricultura indígena, em áreas cultivadas com mandioca é insuficiente para recomposição dos atributos químicos de um Espodossolo Ferrocárbico.

Áreas com floresta natural ou que passaram pelo pousio de um, dois ou três anos apresentam $\mathrm{pH}$ menos ácido que as áreas de mandioca recém-colhida.

Os manejos de pousio adotados não diminuem a saturação por $\mathrm{m}$ dos solos, o que evidencia a necessidade de correção química do solo para a recomposição da fertilidade.

\section{REFERÊNCIAS}

ALVES, M. C. S.; MOREIRA, M. A. B.; CHAGAS, M. C. M.; HOLANDA, J. S.; SILVA, J.; LIMA, LIMA, J. D. S. Recomendações técnicas para o cultivo da mandioca. Natal - RN, 2009. <http://docslide.com.br/documents/cartilha-cultivo-damandioca.html>. Acesso em: 08/10/2015.

BETENCOURT, E.; DUPUTEL, M.; COLOMB, B.; DESCLAUX, D.; HISINGER, P. Intercropping promotes the ability of durum wheat and chickpea to increase rhizosphere phosphorus availability in a low P soil. Soil Biology \& Biochemistry, v.46, p.181-190, 2012. Disponível em:<http://www.sciencedirect.com/science/article/pii/S003807171100407X >. Acesso em: 07/10/2015. doi:10.1016/j.soilbio.2011.11.015.

CIOTTA, M. N.; BAYER, C.; FONTOURA, S. M. V.; ERNANI, P. R.; ALBUQUERQUE, J. A. Matéria orgânica e aumento da capacidade de troca de cátions em solo com argila de atividade baixa sob plantio direto. Ciência Rural, Santa Maria, v.33, n.6, p.1161-1164, nov-dez, 2003. <http://www.scielo.br/scielo.php?script=sci_arttext\&pid=S0103-84782003000600026 $\& \operatorname{lng}=$ pt\&nrm=iso.http://dx.doi.org/10.1590/S0103-84782003000600026. Acesso em: 08/10/2015.

DAROLT, M.R.; OSAKI. F. Efeito da cinza de caieira de cal sobre a produção da aveia preta, no comportamento de alguns nutrientes. $1991,33 p$. In: Calagem \& Adubação. Campinas, SP: Instituto Brasileiro de Ensino Agrícola, 1991.<http://www.iapar.br/arquivos/File/zip_pdf/darolt_cinzacaieira.pdf>. Acesso em: 08/10/2015.

EMBRAPA - EMPRESA BRASILEIRA DE PESQUISA AGROPECUÁRIA. Sistema Brasileiro de Classificação de Solos. Ed. rev. ampl. Brasília: Embrapa, 2013, 353 p.

EMBRAPA - EMPRESA BRASILEIRA DE PESQUISA AGROPECUÁRIA EMBRAPA. Manual de métodos de análises do solo. 2. ed. Rio de Janeiro, $212 \mathrm{p}$. 
1997.

EMPERAIRE, L.; VELTHEM, L. H. V.; OLIVEIRA, A. G. D; SANTILLI, J.; CARNEIRO da CUNHA, M.; KATZ, E. Dossiê de registro do sistema agrícola tradicional do Rio Negro. Brasília: ACIMRN/IPHAN/IRD/Unicamp-CNPq, 235 p. 2010. $<$ http://portal.iphan.gov.br/uploads/ckfinder/arquivos/Dossie_sistema_agricola_rio_ne gro.pdf>. Acesso em: 08/10/2015.

EMPERAIRE, L. Agrobiodiversidade e sistemas agrícolas tradicionais. Magistra, Cruz das Almas-BA, v. 25, I RGVNE, p. 1-5, nov. 2013. <http://www.mma.gov.br/estruturas/sbf_agrobio/_publicacao/89_publicacao21092009 104952.pdf $>$. Acesso em: 08/10/2015.

EMPERAIRE, L.; ELOY, L. Amerindian Agriculture in an Urbanising Amazonia (Rio Negro, Brazil). Bulletin of Latin American Research, v. 34, n. 1, p. 70-84, 2015. $<$ http://onlinelibrary.wiley.com/doi/10.1111/blar.12268/pdf >. Acesso em: 08/10/2015.

FERREIRA, D.F. Sisvar: a computer statistic alanalysis system. Ciência e Agrotecnologia. v. $35, \quad$ n. 6 , p. 1039-1042. 2011. Disponível em: <http://www.scielo.br/pdf/cagro/v35n6/a01v35n6.pdf>.

http://dx.doi.org/10.1590/S1413-70542011000600001. Acesso em: 08/10/2015.

FOIRN - Federação das Organizações Indígenas do Rio Negro. Manejo do mundo: conhecimentos e práticas dos povos indígenas do Rio Negro, Noroeste amazônico/organização Aloisio Cabalzar; colaboração Beto Ricardo, Lucia Alberta. São Paulo: ISA - Instituto socioambiental; AM: - (Conhecimento indígenas, pesquisas interculturais 1). São Gabriel da Cachoeira, 2010.

FRASER, J. A. Caboclo horticulture and Amazonian dark earths along the middle Madeira River, Brazil. Human Ecology, v. 38, n 5, p. 651-662, 2010. <http://link.springer.com/article/10.1007\%2Fs10745-010-9338-y\#/page-1>.DOI: 10.1007/s10745-010-9338-y. Acesso em: 08/10/2015.

FRASER, J. A.; PEREIRA, A. A.; ANDRE' B.; JUNQUEIRA, N. P.; CLEMENT, C. R. Convergent adaptations: Bitter manioc cultivation systems in fertile anthropogenic dark earths and floodplain soils in Central Amazonia. PloS One, v. 7, n. 8, 2012. $<$ http://www.plosone.org/article/fetchObject.actionuri=info:doi/10.1371/journal.pone.0 043636\&representation=PDF $>$. Acesso em: 08/10/2015.

FREITAS, C. G.; FARIAS, C. S.; VILPOUX, O. F. A produção camponesa de farinha de mandioca na Amazônia sul ocidental. Boletim Goiano de Geografia, v. 31, n. 2, p. 29-42, 2011. <http://www.revistas.ufg.br/index.php/bgg/article/view/16843/10253. DOI 10.5216/bgg.V31i2.16843>. Acesso em: 08/10/2015.

GROXKO, M. Mandiocultura. Análise da conjuntura agropecuária 2011/12. Curitiba: Secretaria de Agricultura e do Abastecimento/PR. Disponível em: $<$ http://www.agricultura.pr.gov.br/arquivos/File/deral/Prognosticos/mandiocultura_201 3_14.pdf>. Acesso em: 08/10/2015.

GUIMARÃES, B. V. C.; SOUZA, E. B., ABREU, A. M. A., DONATO, S. L. R., ENCICLOPÉDIA BIOSFERA, Centro Científico Conhecer - Goiânia, v.11 n.22; p.384 
ASPIAZU, I. CAPTAÇÃO E APROVEITAMENTO DA ÁGUA DA CHUVA PARA FINS NÃO POTÁVEIS E POTÁVEIS. Enciclopédia Biosfera., v. 11, p. 2926 - 2939, 2015. <http://www.conhecer.org.br/enciclop/2015b/multidisciplinar/Captacao\%20 \%20Aproveitamento.pdf>. Acesso em: 08/10/2015.

IBGE- Instituto Brasileiro de Geografia e Estatística. Levantamento Sistemático da $\begin{array}{llll}\text { produção Agrícola. } & & & \end{array}$ <http://www.ibge.gov.br/home/estatistica/indicadores/agropecuaria/lspa/>. Acesso em: 08/10/2015.

LORENZI, J. O.; OTSUBO, A.A.; MONTEIRO, D. A; VALLE, T. L. Aspectos fitotécnicos da mandioca em Mato Grosso do Sul. In: OTSUBO, A.A.;

MAGALHÃES, A. G.; ROLIM, M. M.; DUARTE, A. S.; TAVARES, U. E.; PINHEIRO, L. C.; LEITÃO, D. A. H. S. Reutilização da água residuária de casa de farinha em substituição à adubação mineral: efeitos no solo e na planta. EDUCAmazônia, v. 10, n. 1, p. 93-108, 2013. <http://dialnet.unirioja.es/servlet/articulo?codigo=4709247>. Acesso em: 08/10/2015.

MATTOS, P. L. P.; BEZERRA, V. S. Cultivo da mandioca para o estado do Amapá. In: EMPRESA BRASILEIRA DE PESQUISA AGROPECUÁRIA. Centro Nacional de Pesquisa de Mandioca e Fruticultura. Cruz das Almas. Sistemas de Produção, v.2,2003.<http://sistemasdeproducao.cnptia.embrapa.br/FontesHTML/Mandioca/man dioca_am apa/>. Acesso em: 08/10/2015.

MAZOYER, M.; ROUDART, L. História das agriculturas no mundo. Do neolítico à crise contemporânea. São Paulo: Editora UNESP; Brasília: NEAD, 2010. <http://w3.ufsm.br/gpet/files/Historia\%20das\%20agriculturas\%20no\%20mundo\%20\%20Mazoyer\%20e\%20Roudart.pdf>. Acesso em: 08/10/2015.

MERCANTE, F. M.; MARTINS, C. de S. (Coord.). Aspectos do Cultivo da Mandioca em Mato Grosso do Sul. Dourados/Campo Grande: Embrapa $\begin{array}{lllll}\text { Agropecuária } & \text { Oeste/UNIDERP, } & \text { p. } & \text { 77-108. }\end{array}$ $<$ http://ainfo.cnptia.embrapa.br/digital/bitstream/item/38819/1/LV20021.pdf>. Acesso em: 08/10/2015.

OTSUBO, A. A.; MERCANTE, F. M.; MARTINS, C. S. Aspectos do cultivo da mandioca em Mato Grosso do Sul. Dourados: Embrapa Agropecuária Oeste; Campo Grande: UNIDERP, 2002. <http://ainfo.cnptia.embrapa.br/digital/bitstream/item/38819/1/LV20021.pdf>. Acesso em: 08/10/2015.

PARRY, M. M.; DE CARAVALHO, J. G.; KATO, M. D. A.; VIELHAUER, K. Estado nutricional da mandioca cultivada em diferentes épocas sob cobertura morta e duas adubações.Revista Ciências Agrárias, Belém, n. 43, p. 91-114, 2005. $<$ http://ainfo.cnptia.embrapa.br/digital/bitstream/item/38678/1/Revista-CienciasAgrarias-43-91-114.pdf>. Acesso em: 08/10/2015.

PIPERNO, D. R. The origins of plant cultivation and domestication in the New World Tropics: patterns, process, and new developments. Current Anthropology, v. 52, n. 
S4, p.

453-470,

2011.

$<$ http://anthropology.si.edu/archaeobio/images/piperno_ca_2011.pdf >. Acesso em: 08/10/2015.

RÓS, A. B. Produtividade de raízes de mandioca em função de doses de potássio. Pesquisa \& Tecnologia, v. 9, n. 1, 2012. <http://www.aptaregional.sp.gov.br/acesseos-artigos-pesquisa-e-tecnologia/edicao-2012/janeiro-junho-2/1170-produtividade-deraizes-de-mandioca-em-funcao-de-doses-de-potassio/file.html>.DOI:

http://dx.doi.org/10.17766/1808-981X.2013v9n1p25-32. Acesso em: 08/10/2015.

SALLA, D. A.; CABELLO, C. Análise de desempenho energético dos cultivos da mandioca, cana-de-çúcar e milho em função da extração/exportação de macronutrientes para produção sustentável de etanol. Revista Raízes e Amidos Tropicais, $\quad$ v. $3, \quad n$. 2007.<http://revistas.fca.unesp.br/index.php/rat/article/view/1162>. DOI: http://dx.doi.org/10.17766/1808-981X.2007v3n1p9-12. Acesso em: 08/10/2015.

SAMPAIO, F. A. R.; FONTES, L. E. F.; COSTA, L. M.; JUCKSCH, I. Balanço de nutrientes e da fitomassa em um Argissolo Amarelo sob floresta tropical amazônica após a queima e cultivo com arroz.Revista Brasileira de Ciência do Solo, $\square$ v. 27, n. 6, p. 1161-1170, 2003. <http://www.scielo.br/pdf/rbcs/v27n6/19210.pdf>. Acesso em: 08/10/2015.

SILVA, H. A \& MURRIETA, R. S. S. Mandioca, a rainha do Brasil? Ascensão e queda da Manihot esculenta no estado de São Paulo. Bol. Mus. Para. Emílio Goeldi. Cienc. Hum., Belém, v. 9, n. 1, p. 37-60, jan/abr.2014. <http://www.scielo.br/pdf/bgoeldi/v9n1/04.pdf>. Acesso em: 08/10/2015.

TRINDADE, R. S.; ARAÚJO A. P.; TEIXEIRA, M. G. Leaf area of common bean genotypes during early pod filling as related to plant adaptation to limited phosphorus supply. Revista Brasileira de Ciência do Solo, v.34, p.115-124, 2010. <http://www.scielo.br/pdf/rbcs/v34n1/a12v34n1.pdf.>.

http://dx.doi.org/10.1590/S0100-06832010000100012. Acesso em: 08/10/2015.

ZATARIM, M.; BONO, J. A. M.; NASCIMENTO FILHO, J. S do. Doses de potássio e calcário para mandioca (Manihot esculenta Crantz) em um Neossolo Quartzarênico de Mato Grosso do Sul. XI Congresso Brasileiro de mandioca. 2005. 